\title{
A FORMAÇÃO HUMANÍSTICA DO MÉDICO
}

\author{
HUMANISTIC EDUCATIONAND MEDICAL EDUCATION
}

Isaias Pessotti

Docente do Departamento de Neurologia, Psiquiatria e Psicologia Médica da Faculdade de Medicina de Ribeirão Preto da Universidade de São Paulo.

Correspondência: Departamento de Neurologia, Psiquiatria e Psicologia Médica da Faculdade de Medicina de Ribeirão Preto Campus Universitário - CEP: 14048-900 - Ribeirão Preto - SP - Fone (FAX) 016-633-0866

PESSOTTI I. A formação humanística do medico. Medicina Ribeirão Preto 29: 440448 out /dez 1996

RESUMO: As mudanças históricas no significado social e ético da atividade médica e na Filosofia Humanística tornam difícil propor um conteúdo ideológico para a formação humanística do medico Essa formação e produto das experiências pessoais de cada um e implica a consciência do próprio sistema de valores que delas resultam Implica também a consciência do paciente como um seguidor e criador de valores Sua reação ao tratamento clinico depende também dos significados que ele associou a doença a vida a Medicina Numa escola medica pode se contribuir apenas de modo acessório para aquela formação oferecendo informação sobre assuntos humanísticos e exemplos de fidelidade aos próprios valores e de respeito aos valores do paciente.

UNITERMOS: Ética. Humanidades. Educação Médica. Filosofia Médica.

O tema deste artigo envolve três conceitos importantes. Cada um implica questões graves e requer algumas definições filosóficas que não são simples.

Basta pensar no conceito de médico, por exemplo. Definir o que tem sido o médico na História da Civilização, o que ele é hoje, ou o que deve ser agora e no futuro, é algo que demanda não pouco estudo e reflexão. O papel social do médico variou muito, do século XIX ao nosso tempo, para não mencionar a evolução mais remota do significado do médico na Cultura Ocidental. Uma evolução milenar que tem raízes na medicina sacerdotal pré-hipocrática.

De outro lado, o que significa o atributo humanística? Os múltiplos significados do termo oscilam entre o conceito de Homem, já em si um uni verso de questões, e o conceito de Humanidades, entendidas como território, vastíssimo, do saber. O conceito de Homem, do Iluminismo, é radicalmente diverso de conceitos correntes na Antigüidade Grega ou na Cultura Medieval ou, ainda, nos tempos do Renascimento.
Mais diverso ainda, na era da informática e da automação. As Humanidades, enquanto conjunto, aberto, de ciências estão, pois, em permanente redefinição de rumos, critérios e métodos.

Considere-se, além disso, o conceito de formação. Tomado na sua acepção etimológica e literal, dar forma, o conceito implica, de saída, a existência de algo, com a função de suporte, algo com o estatus de matéria, à qual se impõe a forma. Uma relação paralela à que liga substância e atributo, genérico e específico, caos e delimitação, incerteza e definição.

Também a conotação pedagógica do termo, e que nos interessa mais de perto, é necessariamente ancorada num sistema de valores e numa definição de fins que varia em cada época. Formar alguém, pelo processo de educação, não significa hoje o que significou nos tempos de Galeno, da Escola de Salerno, na Universidade Medieval ou nos tempos do Renascimento ou na época de Claude Bernard. 
Essas considerações oferecem uma amostra da complexidade das muitas questões que o tema deste trabalho implica. Algumas delas serão tratadas, a seguir, agrupadas em três tópicos:

a) O sentido da Medicina;

b) A Filosofia Humanística e as Humanidades e

c) A formação humanística do médico.

\section{O SENTIDO DA MEDICINA}

Desde os tempos pré-homéricos, a fragilidade da vida ou, por outro lado, a certeza da finitude marca o pensamento humano, em suas várias modalidades. A consciência de que a morte chegará e de que a vida pode esgotar-se num minuto, foi sempre uma fonte de inquietação ou de ansiedade. (Não importa, neste ponto, que já na Grécia antiga como na Roma dos estóicos essa ansiedade fosse negada, através de uma ética da resignação, de abandono aos desígnios de algum logos supremo).

Similarmente, a dor e os sofrimentos corporais inexplicados, ou explicados através do mito ou da magia, foram sempre outras causas de ansiedades que se procuravam atenuar com rituais propiciatórios ou com o apelo a quem pudesse, bafejado pela divindade, aplacar as forças hostis da natureza corporal, através de algum phármakon, da imposição das mãos, ou de alguma dieta mágica, penitencial.

Não é de admirar que a figura que ostentasse poderes de salvar a vida ou aliviar a dor, fosse a que mais próxima estivesse dos poderes da divindade, Os primeiros médicos foram, como se sabe, os sacerdotes que, nas várias culturas, desde o século VIII a.C., pelo menos, inspirados ou credenciados pelos deuses, praticavam a arte de curar.

E enquanto delegados da divindade, ministros dela, os sacerdotes-médicos eram os mesmos que decidiam e doutrinavam em matéria de ética, de convivência humana ou, noutros termos, de ética social. A Medicina era uma atividade divina, exercida pelos deuses com a mediação sacerdotal. A arte médica era uma função religiosa do sacerdote, e como tal, indiciada dos valores e crenças a respeito do homem e seu destino.

Em termos de hoje, dir-se-ia que a Medicina era uma emanação da Filosofia Humanística ou, tal vez mais precisamente, da concepção de homem no universo teológico da época.

O pensamento médico de Hipócrates, que revoluciona esse panorama, que marca o princípio do fim da Medicina Sacerdotal, deveria ocorrer na segunda metade do século $\mathrm{V}$ a.C., quase a coroar o apogeu do que se chamou o Iluminismo Grego. A doutrina do mestre de Cós nasce ao lado da florescente Filosofia Socrática, no terreno fértil da inteligência ática.

A Medicina Hipocrática e a Filosofia do Homem cresceram juntas, no luminoso "século de Ate nas". Doutrina e prática médica, de um lado, e filosofia do homem e ética, de outro, foram produtos de um mesmo clima cultural.

Tanto a Medicina Hipocrática como a Filosofia Humanística de Sócrates, por se fundarem na experiência pessoal e no apego à racionalidade, esvaziavam os poderes do mito e do dogma, enfeixados pela classe sacerdotal.

Já na primeira metade do século $\mathrm{V}$, Anaxágoras e depois Eurípides, haviam começado a desnudar a ingenuidade do mito. Quando Anaxágoras afirma que o Sol não é um deus mas um globo de rocha incandescente; quando Eurípides afirma que não são os deuses, mas as forças naturais da paixão que levam os homens ao ódio, ao homicídio ou heroísmo, à covardia, o apelo cômodo ao mito já não justifica nem isenta o homem de sua culpa ou de sua fraqueza, nem o dogma basta para dar poderes e saberes superiores.

Agora, a morte, a dor, a finitude se apresentam despidas de qualquer idealização mítica: são contingências naturais. $\mathrm{O}$ homem agora tem uma natureza que é sua: aparece, na História da Civilização, a idéia de uma natureza humana.

Como os dogmas e o mito já não explicam nem o Sol nem a doença e a morte, os rituais sacerdotais e os filtros mágicos não bastam como terapêutica.

Assim, a teoria médica naturalística de Hipócrates é indissociável da idéia de natureza humana, não só no plano da evolução cultural, mas, também, no nível da implicação lógica. Não se discutirá aqui, a bem da brevidade, quanto o Corpus Hippocraticum está impregnado de elevado sentido moral e de uma fidelidade quase ascética aos ditames da racionalidade. No famoso juramento de Hipócrates, a postura ética aparece em várias passagens, mas, especial mente, nesta: "Conservarei pura e pia a minha vida e a minha arte"; a negação de poderes e deliberações transcendentes, ou o apego à racionalidade, aparece numa expressão que se repete: "agirei segundo o meu poder e o meu juízo".

Também a busca ética do dado empírico, como elemento essencial para o diagnóstico, espelha, no nível das funções orgânicas, a ética, socrática, do 
"conhece-te a ti mesmo". Desse modo, a Medicina Naturalística nasce como produto de uma nova postura intelectual que poderia chamar-se uma "revolução socrático-hipocrática".

No pensamento de Hipócrates (como, mais tarde, no de Galeno) pareceria estranha uma distinção entre formação médica e formação humanística. $\mathrm{O}$ médico é, antes de tudo, um homem aperfeiçoado pela ética e pelo saber a respeito da natureza humana. Ele é, necessariamente, um humanista.

O galenismo, graças aos seus vários pneumas, manterá, num mesmo sistema vital, os processos orgânicos e as atividades afetivas e cognitivas do homem, alguma forma de equilíbrio e convivência entre a alma, a mente e as funções fisiológicas. Manterá uma doutrina médica que entende o corpo como instrumento de percepção e de ação, controlado pelos desejos, valores e emoções. A arte médica permanece, com Galeno, indissociada de uma visão mais ampla do Homem. Uma visão não mais teológica, mas, filosófica, como tinha sido, aliás, a de Hipócrates.

É só muito mais tarde, no século XVII, que o saber médico se afasta da Filosofia do Homem, graças ao dualismo da Fisiologia Cartesiana, bem como ao florescimento das ciências naturais e do espírito científico. A doutrina de Descartes institui a separação entre uma vida subjetiva (implicando sentimentos, valores e cognições) e uma vida objetiva do corpo, regida pelas leis da Física e da Química, como qualquer substância extensa. Esse dualismo, que, na tradição galenista, se evitara a todo custo, cria para a Medicina um vasto programa de pesquisa e atuação que pode, então, prescindir de qualquer doutrina sobre processos subjetivos e, o que é mais decisivo, pode ignorar a marca definitiva do humano: a criação de valores e o apego a eles. O homem, que julga, sofre, escolhe e avalia, não pertence mais ao saber médico. $\mathrm{O}$ homem anatomofisiológico se destaca do homem filosófico.

Noutros termos, a Medicina pode agora se ocupar apenas da inachine humaine. Com a mesma objetividade e amoralidade que ostenta o saber físico ou astronômico. Agora, os valores atribuídos à arte médica, o sentido da Medicina ou a própria ética médica, passam a ser uma exigência extrínseca ao saber propriamente médico. Agora se pode ser um médico competente, mesmo sem referência a qualquer sistema ético ou filosófico. O médico não precisa ser um humanista. Ele lida, agora, meramente com eventos físi$\cos$, materiais.
O florescimento do espírito científico e das ciências naturais, também típico dos séculos XVII e XVIII teve, entre outros, o mérito de banir o controle autoritário da pesquisa e dos critérios de verdade, Os gênios da latroquímica, da Medicina Pneumática ou da latromecénica fundaram um saber médico liberto de conceitos espiritualistas, principalmente depois que Baglivi, em 1700, demonstra a ausência de ação da alma no movimento muscular, mostrando que "in contractionis negotio nulias haberet anima partes".

Mas a atitude de rejeitar os conceitos de tipo espiritualista teve outros efeitos, colaterais: de um lado, o banimento da alma não eliminou a especulação metafísica (de certo modo, até a estimulou); de outro, aquela atitude produziu uma desqualificação de saberes que, por não ostentarem base empírica reconheci da, foram relegados ao limbo, ou à margem da florescente "Ciência".

Enquanto arte decisiva para a sobrevivência do homem, a Medicina precisava agarrar-se, até por de ver de ofício, à pesquisa científica balizada pelo mais rigoroso empirismo. Se a Ciência trata apenas do que se pode observar empiricamente, só há conhecimento seguro sobre objetos concretos. E, então, o saber médico passou a rejeitar, como ilegítimas, quaisquer questões relativas à subjetividade humana, aos valores do homem e, até, à significação última (ou apenas social) de sua arte.

Só mais tarde esses saberes ganhariam a qualificação de Ciências Humanas ou Humanidades. Isso quando ficou claro que o inobservável pode também ser natural. Ou, quando se percebeu que, talvez, a maior parte dos fenômenos naturais não se pode observar diretamente. E que, portanto, a teoria que harmoniza os produtos da observação empírica e que dirige a praxis, pode ser metafísica.

Na euforia cientificista dos séculos XVII e XVIII (e que persiste hoje no discurso ou no pensa mento de cientistas até respeitados, mas; ingênuos), o método científico aparecia como instrumento definitivo de domínio da natureza circunstante, não menos que da natureza anatomofisiológica do homem. Era o triunfo da racionalidade. Nesse tempo, tudo o que há de contingente, de convencional, de incerto, de subjetivo, de ideológico, em qualquer produto científico, era insuspeitado. Os inevitáveis limites e distorções de uma sonhada e asséptica objetividade também não eram vislumbrados.

Uma crítica da Ciência era ainda preocupação, negligenciável, de alguns poucos filósofos, também 
negligenciáveis aos olhos dos empolgados desbrava dores do desconhecido.

Mas o prestígio social do médico-cientista dos séculos XVII e XVIII não é muito menor que o do antigo médico-sacerdote. Com algumas diferenças: ele não é mais uma autoridade moral, não é um ministro do divino, depositário de poderes que independem do conhecimento dos homens. Ele é apenas alguém que detém um saber, até idealizado, e pode, com esse saber, produzir cura e alívio. Pode trazer sobrevivência e tranqüilidade. Mas seu saber não tem significados. Pode ter, apenas, efeitos, O médico agora não é mais significante do que um policial ou um bombeiro. Também estes, de fato, podem salvar a vida e trazer segurança.

A base científica assegura ao saber médico e à arte médica uma certa probabilidade de eficácia curativa, sobre os órgãos e suas funções, mas nenhum significado filosófico ou ético especial. Certamente, aos olhos do povo carente de cura, a arte médica preserva uma certa respeitabilidade. Mas este prestígio, agora, não decorre da autoridade moral do médico, mas de um generalizado culto à Ciência, de um respeito, até tímido, por quem domina técnicas de inter vir sobre os órgãos do corpo e suas funções. O médico não trata mais de homens, trata de corpos doentes. Mesmo quando procura entender "o paciente como um todo" ou, noutros termos, mesmo quando trata do "doente e não da doença". Porque tudo o que não configura o "paciente" ou o "doente", passou a ser estranho ao saber médico.

Na segunda metade do século XX, os avanços da Epistemologia e da Teoria do Conhecimento. a demitização da Ciência, a evolução das ciências humanas, a crítica da metodologia científica colocaram em crise a autoridade que acompanha o depositário de algum saber científico. Na área do saber médico, como noutras, a transitoriedade das verdades e dou trinas, a incessante substituição das variáveis, consideradas cruciais na explicação de um dado fato, a proliferação de resultados experimentais discrepantes ou contraditórios, acabaram por abalar a segurança que o cientificismo oitocentista permitia. O saber médico se revela precário, como qualquer saber científico.

Neste final de século, a prática clínica está a mostrar, todo dia, que, cada vez mais, as patologias mais diversas implicam processos emocionais (que refletem dramas e carências sociais). Um médico clínico (curiosamente, e infelizmente, isso não é mais pleonasmo) percebe que em cada "doente" ou "paciente como um todo" está um homem pressionado pelos dra- mas de sua vida pessoal, por seus conflitos de valores e desejos, pelas exigências penosas da vida social. Este médico percebe que aAnatomofisiologia, a Patologia, e os vários saberes especializados que hauriu na formação acadêmica não o socorrem. Percebe que está formado para entender um paciente padrão, um paciente teórico, virtual, que não existe, que não é o que comparece no consultório ou no ambulatório.

O médico foi preparado, mais ou menos adequadamente, para tratar um paciente que não é um homem, é um corpo humano. E se defronta, na realidade, com um homem que tem um corpo que sofre, $\mathrm{e}$ este corpo está reagindo fisiologicamente a toda uma gama de influências concretas de tipo emocional, cultural e moral.

Nesta hora, em pleno final do século XX, a Medicina está desnorteada, o saber médico apresenta-se mutilado. A própria eficácia clínica agora está a exigir que se entenda o "homem que está doente". Para a eficiência médica, já não basta entender o corpo, nem basta entender o "doente".

O sentido da Medicina, hoje, não se esgota no enquadramento do caso concreto de um certo paciente em quadros clínicos já estabelecidos e para os quais a terapêutica já está definida a priori, tal como ocorria no século XVIII ou no início do nosso século.

É a própria arte médica que depende, agora, de urna volta ao estudo do homem, para além do conhecimento da niachine huinaine. Aliás, a clínica médica tende a ser, cada vez mais, uma ação do médico sobre o homem integral e menos sobre a máquina orgânica. Mesmo porque essa máquina responderá, fatalmente, às emoções, conflitos e ansiedades que são a marca (até ontológica, segundo o Existencialismo) do homem.

Como se vê, o sentido da Medicina mudou mui to, da antigüidade até nós. De função divina, delega da ou não, passou a ser, com Hipócrates, uma extensão ética da Filosofia Socrática do Homem. Depois, desde o alvorecer das ciências experimentais, distanciou-se do sentido filosófico enquanto saber, e dos valores éticos enquanto praxis: passou a ser apenas um conhecimento científico da natureza corporal do homem, com a resultante praxis dirigida apenas a restaurar o funcionamento orgânico lesado ou desviante.

Parece que o sentido da Medicina, hoje, é obs curo; a menos que se lhe atribua, como sentido, a mera aplicação clínica das descobertas experimentais. Enquanto saber teórico, hermenêutico, ela seria a competência diagnóstica para detectar sintomas e agrupálos em quadros clínicos: algo que já se atribui aos com- 
putadores. Enquanto clínico, o médico seria um técnico de alto nível capaz de prescrever e administrar os produtos da pesquisa experimental. Não é pouco, mas é algo não muito diverso do que respeitar a posologia e as contra-indicações de uma bula de re médio ou de uma dada conduta. Afinal, para isso, não seria necessário todo o curso médico.

Nas últimas décadas deste século, percebe-se, a carência de um conhecimento mais seguro de aspectos não orgânicos do homem se impõe como exigência da própria eficiência médica.

\section{A FILOSOFIA HUMANÍSTICA E AS HUMANIDADES}

Já não é consensual a idéia de que o homem se distingue dos demais seres animais, pela sua racionalidade, e por suas funções intelectuais. Isto porque, a racionalidade o trai ou lhe falta e porque, embora em grau mais baixo, aprendizagens complexas, alguma capacidade de inferência, formação de conceitos, memorização, discriminações complexas e generalizações podem ser demonstradas também noutras espécies. O que distingue radicalmente o homem é a sua capacidade de atribuir significados lógicos e emocionais aos objetos e às ações: é a sua capacidade de instituir valores. Um objeto qualquer pode tornar-se moeda de troca, beleza, ameaça, garantia de afeto, fonte de tristeza, de prazer, de alegria, de medo, de orgulho. O gesto que, numa cultura, produz lágrimas de tristeza, numa outra, causa excitação, ou medo.

Mas não só cada cultura, também cada homem, institui seus valores morais, estéticos, políticos, profissionais, etc. São os valores que constituem a essência do "modo de pensar", do "modo de ver as coisas", da personalidade ou da individualidade pessoal de cada homem. Nisso nada vai de mágico ou metafísico: os valores nascem da experiência pessoal com os objetos, atos e eventos. (A educação aqui se entende como um recurso de programação de experiências pessoais).

Se o humano se distingue, definitivamente, pelo poder de criar e perseguir valores, qualquer formação humanística terá como fundamento o conhecimento do processo de valoração ou, pelo menos, da existência desse processo, na gênese do que se chama homem. A faculdade de criar valores, de julgar e de apreciar, entendida como distintivo do humano, é a pedra angular da filosofia de Sócrates e dos sofistas, ao afirmarem que o "homem é a medida de todas as coisas".
Este princípio é indissociável de dois outros: o de responsabilidade pessoal pelos erros de conhecimento e de conduta, já que os deuses agora saem de cena, e o da relatividade das certezas e dos valores, já que o outro homem também é uma "medida de todas as coisas".

É em torno desses princípios basilares que a Filosofia Humanística evolui desde a Antigüidade Grega até aos tempos medievais da ditadura teocrática em matéria de conhecimento e de moral. No Renasci mento e no século XVII, a filosofia do homem, nova mente livre, retoma, como problemas prioritários a questão dos critérios de certeza, ou de correção ética, e a das relações entre conhecimento e ética. É em torno desses temas que se constrói a obra fundamental dos três gigantes da Filosofia Seiscentista: Descartes, Spinoza e Pascal.

Os grandes sistemas filosóficos dos séculos XVIII e XIX procurarão combinar a aceitação dessa natureza valorante do homem com a idéia de que o fluxo da História não é apenas resultante da criação científica e valorativa do homem, mas é, também, de terminante do conhecimento e da opção, ética de cada um. É nesse terreno que germinarão as três grandes correntes de pensamento que dirigirão a Filosofia do Homem até as décadas finais deste nosso século: o Historicismo, o Marxismo e o Existencialismo.

Aquele homem que vem ao consultório queixando-se de insônia ou de falta de apetite, é o mesmo homem do "conhece-te a ti mesmo", "medida de todas as coisas", "machine humaine", "caniço que pensa", um homem cuja "existência precede à essência", cujo trabalho produz a "mais valia". Qual desses produtos da Filosofia Humanística interessa à formação do médico? Antes de formular alguma resposta, devese juntar a essas concepções filosóficas de homem, as que as ciências humanas produziram nos dois últimos séculos. Um homem condicionado, na ação e no pensamento, pelos eventos de sua história pessoal, um homem imune às determinações do ambiente, ou um homem dirigido por motivações inconscientes, ou depositário de indefinidas tendências genéticas para querer, pensar ou fazer isto ou aquilo! Um homem cujo conhecimento e cuja ética é produto da infraestrutura econômica via luta de classes? Um homem alienado pelo sistema capitalista de produção, massificado, despersonalizado, consumidor manipulado pelas leis do mercado, conduzido a pensar e a querer o que a "mídia" lhe impõe? 
Segundo a concepção que escolhermos, dentre essas todas, a formação humanística do nosso médico deverá incluir o conhecimento da filosofia existencialista, ou da teoria econômica marxista ou, da teoria psicanalítica, do neo-behaviorismo ou, porque não, várias dessas áreas do saber humanístico. Qual a saí da, nesse labirinto de caminhos? Qual o conhecimento humanístico que mais convém a um médico que vai clinicar no século XXI?

A resposta requer duas ponderações prévias. Primeiro, o conhecimento de diferentes concepções de homem (geradas na Filosofia ou nas Ciências Humanas), mesmo discrepantes ou contrastantes entre si, é fundamental para que a visão humanística do médico escape de algum partidarismo doutrinário, ou do fascínio do dogma bem formulado. Então, o conhecimento humanístico a ser buscado deve ser essencialmente crítico, relativista. Segundo, não é o mero conhecimento, mesmo crítico, desses produtos da indagação de pensadores ou cientistas sociais que as segura uma verdadeira formação humanística: ele garante informação humanística, mais ou menos crítica. Terceiro, a simples informação criteriosa ou crítica já bastaria para uma atuação médica voltada para aspectos humanos, outros que os que compõem a morfologia e a fisiologia da máquina orgânica.

Agora é mais fácil responder à questão posta mais acima. A recusa ao dogma impõe a relatividade do conhecimento. A História ensina a transitoriedade das verdades de qualquer ciência e dos valores morais, estéticos, políticos e outros. A Epistemologia está a indicar a fragilidade dos critérios de cientificidade. Segue-se que nenhuma doutrina é absolutamente verdadeira, nenhum conhecimento é permanentemente válido. a verdade da ciência, além de ser fugaz, é em grande parte convencional. Mais ainda, a história das ciências mostra que, em cada época, o saber melhor possível é apenas a síntese crítica dos saberes precedentes.

A resposta agora é óbvia: quanto mais o médico conhecer as doutrinas ou tendências da Filosofia Humanística de seu tempo, e quanto mais conhecer as teorias científicas sobre o pensamento e o comporta mento humano, mais estará apto a compreender a complexidade do homem que existe para além da morfofisiológica. E quanto mais esse conhecimento se for alterando com informações ulteriores, mais a sua vi são do homem, previamente conseguida, será vista criticamente. Em conseqüência, mais ele estará apto a integrar as informações discrepantes ou contraditórias que são típicas das ciências humanas. (é muito mais fácil haver homogeneidade na observação, e portanto na inferência teórica, em ciências que lidam com objetos físicos invariantes, diretamente mensuráveis e com escassa variabilidade qualitativa).

Certamente, para o jovem médico, o que a Filosofia ou as "ciências do homem" têm a dizer, parecerá pouco mais do que mera especulação, ou até metafísica, depois da informação a crítica do cursinho, depois da objetividade organicista, talvez inevitável, da formação médica. Não é raro que ele se encontre como peixe fora d'água, ao ler algum texto de Sociologia ou de Psicologia ou de Epistemologia ou de História da Ciência. Essa estranheza tem, pelo menos, duas explicações. A primeira é óbvia: ele não foi preparado para aceitar ou entender esse tipo de textos. A segunda é menos evidente: graças ao cientificismo (que impede uma verdadeira informação científica), é fácil que o jovem médico desenvolva uma atitude de menosprezo por áreas do saber que "não lidam com fatos" ou que não levem a conclusões precisas.

Nessa postura se escondem duas mistificações a respeito da Ciência, que suscitam duas objeções. Primeira: não há ciência que lide com fatos. É a natureza que lida com eles. As ciências, todas, sem exceção, lidam com representações de fatos, sempre com algum grau de abstração em relação ao dado bruto. $\mathrm{O}$ conhecimento é, na sua essência, necessariamente, uma representação. Mais, o conhecimento científico é sempre postJ (A rigor, não há conhecimento do que ainda não aconteceu. É sobre o registro do acontecido que se elabora o conhecimento.) Segunda: o emprego de medidas precisas não assegura a validade de um experimento. Uma conclusão muito precisa pode ser absurda, ou totalmente errada, se o controle das variáveis determinantes (independentes e estranhas) não for seguro. (Aliás os estudos pararnétricos, tão prestigiados e cuja função é determinar valores precisos da relação funcional entre variáveis, só têm sentido quando o elenco de variáveis relevantes já estiver solidamente estabelecido).

\section{A FORMAÇÃO HUMANÍSTICA DO MÉDICO}

O que é formar um médico? Uma resposta possível seria: um médico deve ser preparado para dominar conceitos teóricos e técnicas eficazes para curar doenças e afastar a dor. Se definirmos a profissão médica como essa capacidade, a formação se esgota na aprendizagem de teorias e no domínio de técnicas de diagnóstico e de intervenção clínica e/ou cinírgica. 
O médico é, então, alguém apto a preservar ou prolongar ou melhorar a vida biológica dos homens e a afastar a dor e o sofrimento físico.

Assim, a formação médica, não requer mais que um arsenal de conceitos e as técnicas da praxis medica. A eficácia clínica seria, em última analise, a prova da boa formação médica.

Esta última afirmação é discutível. Ocorre que o jovem que escolhe essa carreira, que procura essa formação, não é uma tabula rasa, uma folha em branco: ele tem uma motivação sua, pessoal, para buscar essa profissão. Ele traz valores, que associou ao seu conceito de Medicina, muito antes do ingresso no curso médico. Valores que adquiriu na sua educação e na sua experiência pessoal pregressa. E que, ao longo do curso médico, não estarão esquecidos ou extintos.

No entrechoque com as doutrinas teóricas, com as experiências clínicas, com a realidade dos dramas dos pacientes, com os exemplos dos mestres que ti ver, cada aluno verá seus valores confirmados, nega dos, alterados.

A eficácia ou eficiência clínica não será apenas função da aprendizagem teórica e prática oferecida pelo curso médico: resultará, também, da maior ou menor consonância entre a experiência concreta na prática médica e o sistema de valores professado pelo aluno.

Então, mesmo que se defina a função do médico em termos de eficiência terapêutica, a formação dele requer, também, a consideração de aspectos outros que a mera qualidade da teoria e do treino clínico que lhe são dados.

Além disso, aquela visão da função do médico empobrece muito a real influencia que ele exerce e que, independentemente de quaisquer preferências doutrinárias, é inseparável da função meramente curativa ou "analgésica" do médico. Quando diagnostica uma doença ou prescreve um tratamento, ele está agindo sobre uma pessoa. Que, enquanto tal, traz, para a relação médica, sentimentos, valores e emoções, que de algum modo, e em certo grau, condicionam aquela eficiência clínica. Portanto, a eficiência clínica dependerá de algum tipo de preparação para lidar com aspectos pessoais, não estritamente médicos, dos pacientes.

Mais ainda, aquela definição da atuação médica, que justificaria uma formação para a eficácia terapêutica, encerra uma concepção viesada de vida. De fato, se se entende a vida como a normalidade das funções orgânicas, um profissional que garante essa normalidade é um perfeito médico. Contudo, pode-se entender a vida, não como a ausência de dor e de doenças, ou a normalidade do organismo, mas como a busca do prazer, do equilíbrio afetivo, ou a realização de sonhos e projetos, por exemplo. Na medida em que o prazer e os sonhos são impedidos pela dor ou pelas disfunções orgânicas; ou na medida em que a busca do prazer pode trazer riscos à saúde, a função do médico se amplia e se complica: ele agora lida, querendo ou não, com aspectos existenciais do seu paciente. Mesmo atuando exclusivamente como médico.

Certamente, a formação que lhe servirá, agora, não se pode limitar à boa informação teórica e ao bom treino clínico. Agora, formar o médico é preparar alguém para exercer uma atividade complexa, funda mental para a vida e as realizações da espécie humana e de cada homem.

Posta desse modo, a questão, fica óbvio que o mero domínio de conceitos científicos sobre o organismo humano, com suas funções e disfunções, dificilmente pode ser chamado, per se, deformação. Também não se pode chamar formação ao treino em técnicas de intervenção clínica ou cirúrgica.

Mesmo à margem de qualquer doutrina filosófica ou psicológica, o homem que o médico trata não é um simples organismo em função. Graças à mera fisiologia do sistema nervoso central, cada homem passa a reagir aos objetos, não apenas segundo suas propriedades físicas, mas, segundo os valores que adquiri ram na sua história pessoal e no seu meio cultural.

Seu sistema endócrino, por exemplo, embora balizado por alguns parâmetros anatomofisiológicos, relativamente definidos, reagirá às influências do meio, segundo os valores que elas adquiriram na história peculiar desse homem.

A idéia básica aqui é a de que os valores, ou significados dos objetos, atos, ou eventos, os tornam emotivamente carregados, dotados de valências positivas e negativas e, assim, dotados de função. Os valores passam a exercer algum tipo de determinação, de controle não só sobre as escolhas mais decisivas ou sobre as relações interpessoais: eles atuam também sobre os órgãos e sistemas da machine humaine.

Se, quando a pele de uma criança é espetada por um espinho ou por uma agulha, as estruturas sensoriais e a fibra nervosa reagem às propriedades físicas do estímulo, o sistema nervoso central, necessariamente, reage; também, aos significados ou valores que esse evento possui, graças à história pessoal dessa criança. Em resumo, o homem que o médico trata 
é o velho homem da Filosofia: o homem que é a "medida de todas as coisas", "criador de valores", ex posto às forças da natureza, como um caniço açoita do pelo vento, "mas um caniço que pensa", como escreveu Pascal, e que se assusta.

A machine elabora sua experiência e, em certa medida, determina, ela própria, o seu modo de reagir, ulteriormente, aos estímulos do meio interno e externo.

Tratar a machine humaine implica conhecer, ou, pelo menos, admitir essa individualidade, até fisiológica, de cada homem. Em suma, nenhum médico consegue tratar só do corpo doente, ainda que o pretenda ou professe.

Qualquer relacionamento entre pessoas é, em alguma medida, um encontro (mais ou menos harmônico) entre diferentes sistemas de valores e significa dos que cada uma delas atribui aos objetos, às ações, às palavras.

Assim, na relação médico-paciente, além das determinações mútuas, no nível da comunicação verbal, ocorre um inevitável encontro (ou desencontro) de dois sistemas de valores. Como vimos, o jovem médico, desde antes de sua formação médica, carrega sua escala de valores éticos, estéticos e outros, e não se despe deles na relação profissional com o paciente.

Seu acerto clínico e o benefício que pode fazer ao paciente dependerá, queira-se ou não, de quanto ele for capaz de perceber os significados que a vida, a doença, a figura do médico, a saúde ou a integridade corporal adquiriram na história de vida do paciente. Não se trata de ser humanitário, embora isso também seja desejável: trata-se de ser, em alguma medida, um humanista, um conhecedor, mesmo principiante, do que constitui a essência da chamada natureza humana: a criação de valores, a atribuição de significado e sentido aos eventos e condições da vida.

A formação humanística não equivale, por tanto, ao conhecimento das doutrinas da Filosofia ou das Ciências do Homem a respeito da natureza humana. Ela implica tal conhecimento, mais ou menos amplo. Mas ela é, sobretudo, a capacidade de enxergar e de entender o paciente-homém, o pa ciente com seus valores.

A formação humanística deve capacitar o médico a ver e auscultar não só o corpo enfermo, não somente "o doente" (e não a doença) e não somente o "paciente". Deve prepará-lo para ver e ouvir o homem que está vitimado pela doença e, por isso, traz ao consultório o corpo doente.
Ademais, pode-se inferir, facilmente, do mesmo conceito de homem, não há, a rigor, urna formação humanística do médico. Há urna formação humanística do homem-médico, do homem com todos os seus valores, incluídos os valores que ele atribuiu à Medicina.

Já se pode ver que a formação humanística, aqui tratada, não começa no curso médico. Porque os valores ou significados das coisas, eventos ou pessoas, são produto da experiência pessoal de cada um. A formação do homem começa com seus primeiros sofrimentos e prazeres, sustos e alegrias.

Mas, concretamente, o que nos interessa aqui, suponho, é definir se, quando e como, a educação médica deve contribuir para essa formação já em curso desde a infância de cada aluno.

Quanto ao se, parece óbvio que o programa acadêmico deve contribuir para aquela formação: mesmo porque, a própria eficácia da prática médica vai depender dela. Quanto ao quando, a resposta também parece fácil: já e sempre. Quanto ao como, a resposta é mais complexa.

Concretamente, o que uma escola pode dar, para tal formação, são:

a) cursos (implicando leituras e debates) sobre a filosofia do homem ou sobre a doutrina das ciências humanas (História da Ciência, Psicologia, Antropologia Cultural, Psicologia, etc.)

b) exemplos de como se entende e se trata um paciente humanísticamente.

Na verdade, lembremos, é o aluno que cria seus valores e os cria a partir de suas experiências. O que a escola faz é propiciar experiências com textos, teorias, eventos e com os dramas concretos da vida do paciente. Essas experiências não ocorrem numa tabula rasa mas sobre um sistema de valores já existente. E, então, elas poderão confirmar, contestar ou desmentir, valores previamente criados pelo aluno, e atribuídos à vida, ao outro, à atividade médica, etc. $\mathrm{O}$ que decorre desta consideração? Decorre que a consciência do aluno, de seus próprios valores, de sua própria natureza humana filtrará qualquer experiência, seja programada no currículo escolar, seja estranha a ele.

Portanto o passo inicial de qualquer programa de formação humanística deve desenvolver no aluno a consciência de seus próprios valores, de sua própria humanidade. Pois é essa consciência que filtrará a in formação (curricular ou não) sobre a natureza e a história do homem. 
A capacidade de compreender o outro, dependerá, na clínica e fora dela, do autoconhecimento do futuro médico (como ocorre com qualquer pessoa).

Esta é a experiência fundamental que a formação humanística escolar deve propiciar: o autoconhecimento dos próprios desejos, crenças, carências, de feitos e qualidades. É sobre ele que se construirá o homem-médico, capaz de crescer na interação com o homem-paciente (e com os outros homens).

A informação teórica em disciplinas humanísticas serve apenas para ordenar essa experiência e para organizar racionalmente a percepção do outro e da cultura em que se vive, $O$ produto final de disciplinas como História da Medicina ou Filosofia da Ciência (que conseguimos instituir nesta escola) deve ser a descoberta, pelo aluno, dos valores e sentidos que a humanidade tem atribuído ao homem, à Medicina ou ao conhecimento científico. No confronto de seus valores pessoais com esses que a História e a Filosofia apontam, certamente, o aluno-homem crescerá e o médico humanista começará a se desenvolver.

$\mathrm{O}$ que se deve gerar nesse processo pedagógico é, em suma, a consciência de cada homem-aluno, sobre os valores que ele atribui à Medicina e sobre o próprio projeto de vida, ou seja, sobre os valores que propõe para si mesmo, que identifica como razão de ser da sua vida, de si mesmo. Não se deve pretender que cada médico seja um filósofo ou um sociólogo ou historia dor, mas que seja cada vez mais capaz de compreender os processos maiores que dirigem a vida. $\mathrm{E}$ na situação profissional, que esteja apto a perceber as implicações desse processos para a relação médicopaciente.

Em conclusão: o sentido ou o significado da profissão médica variou muito ao longo da História, e hoje se acha confuso, nebuloso. Oscila entre um cientificismo pragmático, voltado para a mera eficiência fisiológica da praxis e uma vaga admissão de que o homem que recorre ao médico reage, mesmo fisiologicamente, a fatores outros que os da mera economia anatomofisiológica.

De outro lado, a mera informação do médico na doutrina humanística da Filosofia e das Ciências Humanas, não basta para assegurar que sua prática profissional seja mais eficaz ou que lhe traga mais realização ou felicidade pessoal. A verdadeira formação humanística brota das experiências pessoais de cada um, e implica a consciência do próprio sistema de valores (resultante daquela experiência). Implica o autoconhecimento e envolve, também, a consciência do outro (eventualmente, um "paciente") como depositário e criador de valores. Como alguém que reage não apenas ao tratamento clínico mas aos significa dos que, para ele, estão associados à doença, à vida, à Medicina, ao médico.

Concretamente, o que numa faculdade se pode fazer, além de propiciar tempo e meios para informação e debate sobre assuntos humanísticos é dar exemplos de fidelidade aos próprios valores, e de respeito ao outro, paciente ou não, como portador e criador de valores e significados, eventualmente, muito diversos.

PESSOTTI I. Humanistic education and medical education. Medicina, Ribeirão Preto, 29: 440-448, oct./dec. 1996.

ABSTRACT: Historical changes in the social and ethic meaning of medical practice as well as in humanistic thinking of philosophers and social scientists have make it difficult to propose conceptual contents for some humanistic medical education. Such education is the product of personal experiences of each student and implies the consciousness of his system of values, wich results from such experiences. It also implies the consciousness of the patient as another creator of values, and whose reactions to medical care depends on the meanings he has associated to life, to illness, to medical treatment. The Teachers in a medical school, can only otfer an indirect contribution to humanistic improvement of students, through opportunities for discussing humanistic subjects and examples of true respect to their own values and to those of their patients.

UNITERMS: Ethics. Humanities. Education, Medical. Philosophy, Medical. 